III Nordiska

ministerrådet

UNGA

DIREKT

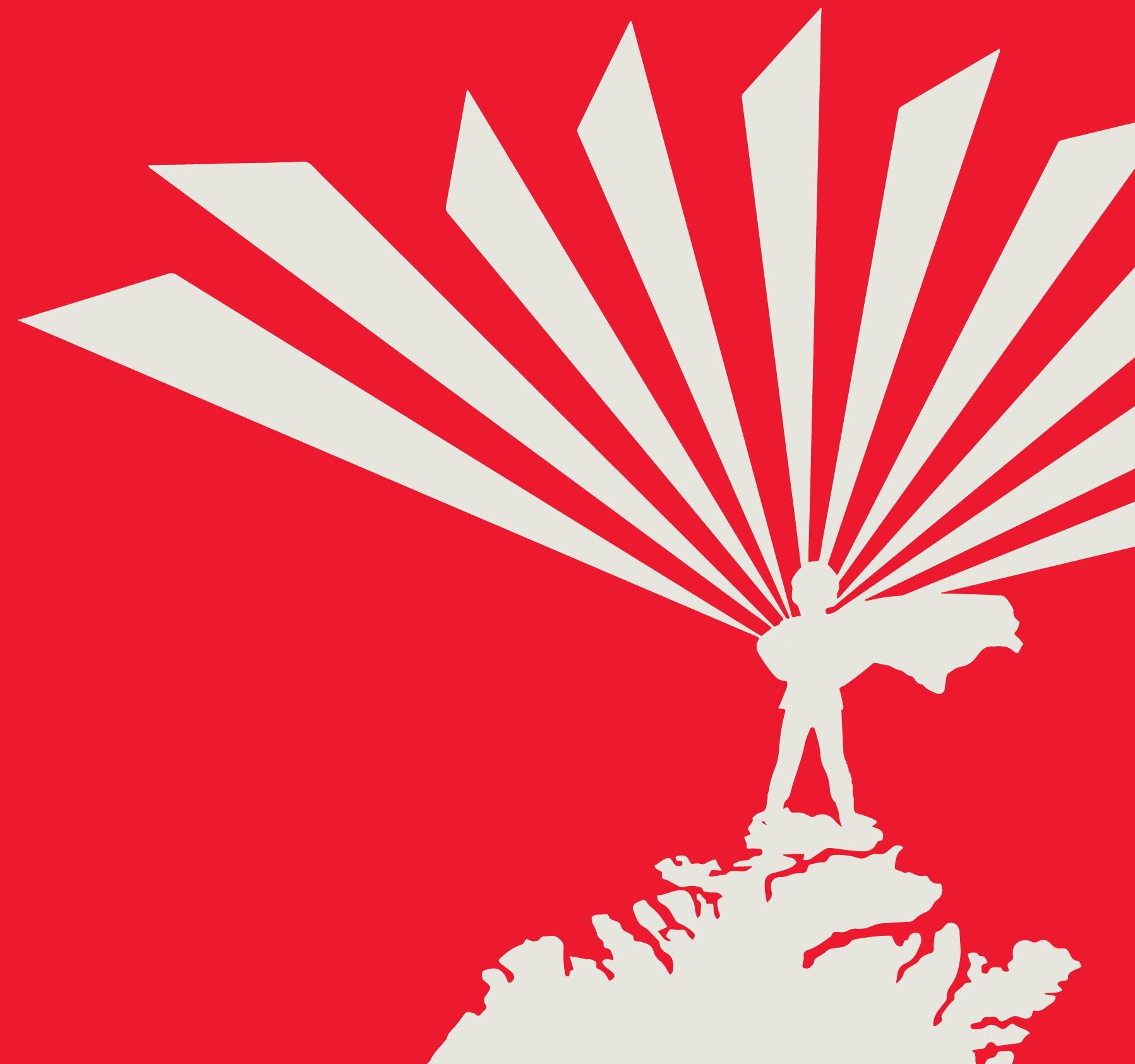




\section{Unga direkt}

Tove Kjellander

ANP 2018:747

ISBN 978-92-893-5536-0 (PDF)

ISBN 978-92-893-5537-7 (EPUB)

http://dx.doi.org/10.6027/ANP2018-747

(c) Nordiska ministerrådet 2018

Layout: Bjørn Ortmann

Omslagsillustration: Saadia Hussain

\section{Det nordiska samarbetet}

Det nordiska samarbetet är ett av världens mest omfattande regionala samarbeten. Det omfattar Danmark, Finland, Island, Norge och Sverige samt Färöarna, Grönland och Åland.

Det nordiska samarbetet är politiskt, ekonomiskt och kulturellt förankrat och en viktig del av europeiskt och internationellt samarbete. Den nordiska gemenskapen arbetar för ett starkt Norden i ett starkt Europa.

Det nordiska samarbetet vill styrka nordiska och regionala intressen och värderingar i en global omvärld. Gemensamma värderingar länderna emellan bidrar till att stärka Nordens ställning som en av världens mest innovativa och konkurrenskraftiga regioner.

\section{Nordiska ministerrådet}

Nordens Hus

Ved Stranden 18

1061 København K

www.norden.org

Ladda ner nordiska publikationer: www.norden.org/nordpub 


\section{EN MYNDIGHET SOM LÄRT SIG LYSSNA}

Namnet "Unga direkt" är en bra ledtråd till syftet med metoden: att hitta och lyfta unga människors röster direkt - utan vuxen justering eller tillrättaläggning. Det är ett ovanligt, men allt mer efterfrågat, tillvägagångssätt för en statlig myndighet. Hos den svenska Barnombudsmannen ligger barns egna erfarenheter till grund för myndighetens rapporter. Utgångspunkten är att barn är experter på sina egna liv och har viktig information att förmedla till beslutsfattare. 
Men allt började i Norge. Metoden från Förändringsfabrikken som beskrivs i publikationen "Do Rights! Nordic perspectives on child and youth participation" har inspirerat den svenska Barnombudsmannen att skapa "Unga direkt". Metoden har löpande anpassats och förfinats under tiden den har använts på myndigheten. I dag har de träffat nästan 1800 barn sedan 2009, producerat ca 20 rapporter som bygger på dessa möten och ordnat ett 20-tal möten mellan de deltagande barnen och beslutsfattare.

Fredrik Malmberg, som tillträdde som barnombudsman i Sverige 2008 och slutade sitt uppdrag 2017, berättar varför myndigheten valde att inleda arbetet.

"När jag tillträdde som barnombudsman var vanvårdsutredningen i fokus. Då berättade nu vuxna personer om hur de hade vanvårdats i social barnomsorg och att skälet till att det kunde fortgå var att ingen hade velat lyssna på deras röster som barn. Det, i kombination med mina erfarenheter från Rädda Barnen i Uganda där vi hade ett stort fokus på att låta makthavare lyssna på barn och unga, bidrog till att jag tyckte att det

\section{OTTOS TIPS TILL VUXNA FÖR ATT LYSSNA PÅ BARN}

$\rightarrow \quad$ Var trevlig mot barnet

$\rightarrow \quad$ Kolla hur barnet mår

$\rightarrow \quad$ Lyssna ordentligt och hör allt barnet säger

$\rightarrow$ Avbryt inte

$\rightarrow$ Ta barnet på allvar

$\rightarrow$ Dra inte förhastade slutsatser, utan lyssna färdigt på vad barnet har att säga

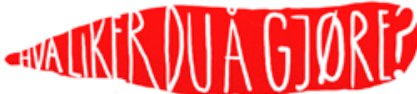

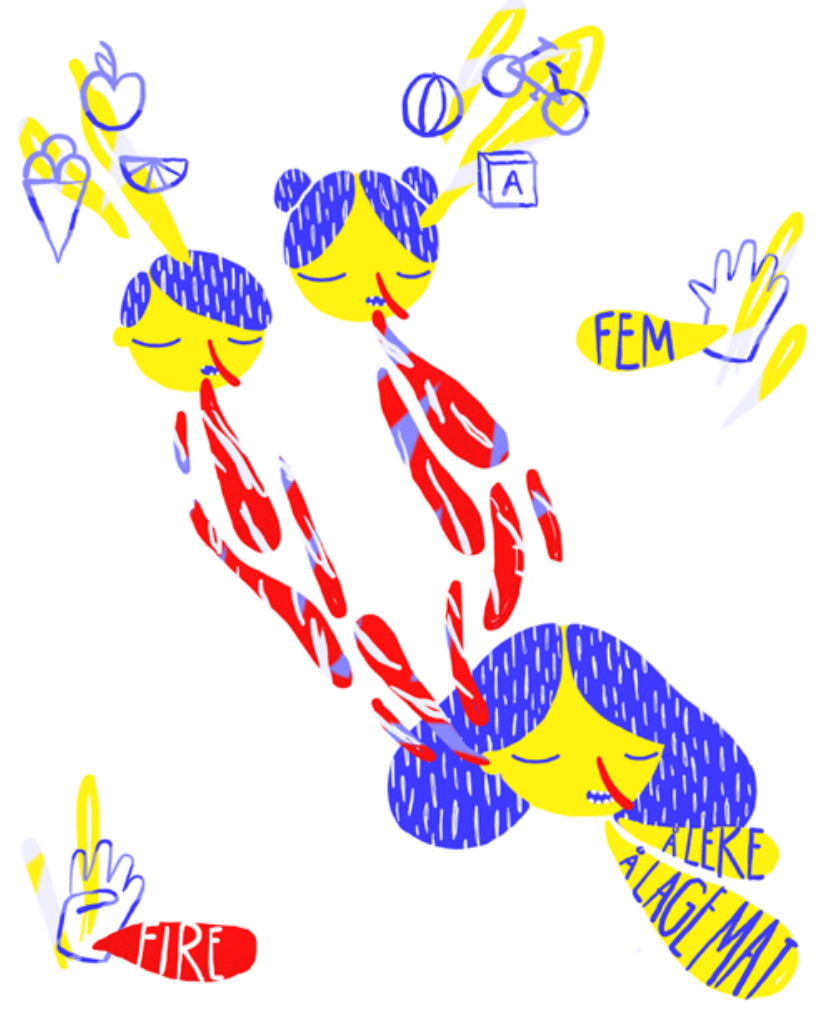

var oerhört viktigt att utveckla vår förmåga att låta barn i svåra situationer få komma till tals på sina villkor," säger Fredrik Malmberg och fortsätter:

"Barn är experter på sina egna liv och har därför viktig information att förmedla till beslutsfattare. Detta är utgångspunkten för svenska Barnombudsmannen, som baserar sina rapporter på barns egna erfarenheter. Metoden "Unga direkt" har som syfte att hitta och lyfta unga människors röster direkt - utan vuxen justering eller tillrättaläggning. Det är en ovanlig, men allt mer efterfrågad metod hos statliga myndigheter. "Unga direkt" är en kvalitativ metod som används för att lyfta enskilda barns erfarenheter. Det som eftersträvas är alltså inte representativitet för alla barn, utan barn som sitter på expertkunskap om en specifik situation." 
"Vi började med att fika lite och bara prata. Sen gick vi in i ett rum och mamma fick vänta utanför. Jag fick bestämma allt i min egen berättelse själv. Jag ritade bilder om mitt liv och sen spelade de in min röst. Och så la vi ihop det jag sa med bilderna så att det blev en film. Det var väldigt kul."

Processen för "Unga direkt" är indelad i sex steg. Grunden är att barnen genom kreativa metoder som till exempel kortfilmer, collage eller dylikt ges möjlighet att berätta om sin situation eller en specifik del av sin livssituation som de vill dela med sig av. I många fall tas det barnen gjort också vidare till direkta möten med beslutsfattare där barnen presenterar det de kommit fram till för till exempel politiker eller tjänstepersoner i en kommun. Fredrik Malmberg berättar att nästan alla möten där makthavare har fått möjlighet att direkt lyssna på barn i svåra situationer har skakat om.

"Vi intervjuade ofta makthavarna och barn före mötena och igen efteråt. Inte sällan trodde makthavarna att mötet skulle bli intressant, men att de ändå redan hade bra koll. Efter dialogen betonade nästan alla makthavare att de var omskakade och att de nu såg ett helt annat värde av direkt dialog med de barn som påverkas av besluten, berättar Fredrik Malmberg."

"Unga direkt" är en kvalitativ metod som används för att lyfta enskilda barns erfarenheter. Det som eftersträvas är alltså inte representativitet för alla Sveriges barn, utan barn som sitter på expertkunskap om en specifik situation, till exempel hur det är att vara placerad, ha en funktionsnedsättning eller ha suttit i häkte. Att myndigheten har valt en kvalitativ metod är ingen slump. Det handlar om att fånga betraktelser, nyanser och fördjupningar som det är svårt att förstå och ta hänsyn till utan att gå på djupet. Genom att lyssna på olika personer som berättar sina personliga historier kring samma tema kan mönster, tendenser och brister upptäckas. Dessa kan sedan kompletteras eller verifieras genom statistik eller andra faktaunderlag. Anna Karin Hildingson Boqvist, vikarierande barnombudsman sedan januari 2018 och tidigare programchef, berättar varför det är viktigt att arbeta med kvalitativa metoder i samtalen med barnen:

"UNGA DIREKT" I SEX STEG

1. Förberedelser

Formulera ditt syfte och förbered dig på det aktuella området

2. Kontakt med barn och unga Kommunicera på ett anpassat sätt vad arbetet går ut på

3. Arbetsträffar

Ha olika sätt för barnen att ta fram budskap

4. Kodning och analys Tolkning av ett kvalitativt material

5. Unga presentatörer Ge beslutsfattare kunskap om barns upplevelser, direkt från barnen

6. Sprida budskapet Sprid kunskapen i organisationen och till relevanta aktörer

Metoden "Unga direkt" finns beskriven i detalj på www.barnombudsmannen. se/unga-direkt 


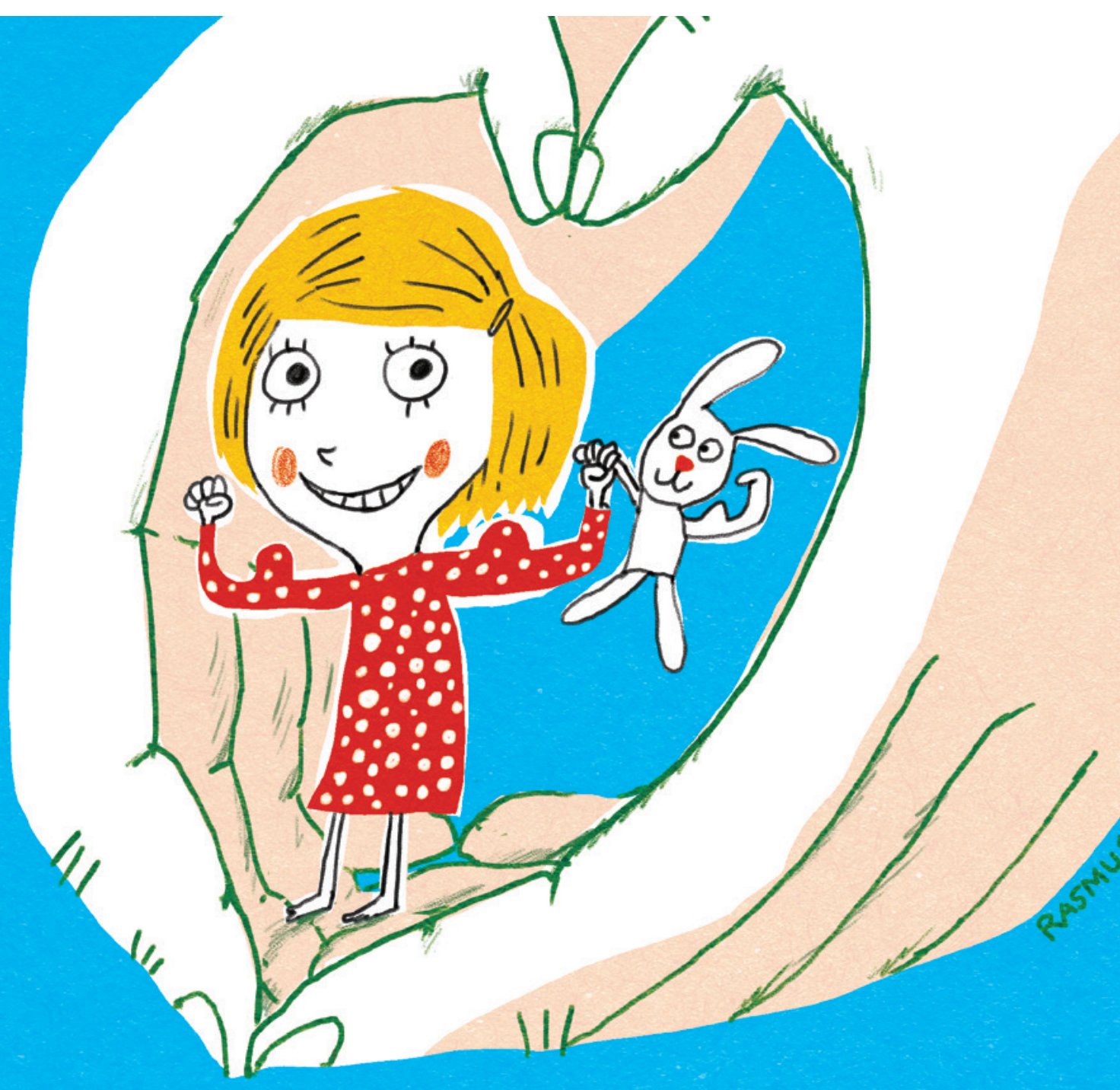

"Att se barn som experter handlar om att vara ödmjuk inför barnets egen unika kunskap och syn på sin situation och lyfta fram barnens egna perspektiv som centrala i processer och beslutssammanhang. Eftersom forskning och myndighetsrapporter visar att barns rätt att komma till tals upprepat brister är det något vi aktivt arbetar med att lyfta fram. För att ta barns rätt till delaktighet på allvar behöver vi vuxna ta oss tid och mod att verkligen lyssna på vad barnen själva har att berätta om sin situation."
Otto arbetade med sin berättelse under nästan en hel dag och är i dag nöjd och stolt över resultatet.

"När jag ser filmen efteråt känner jag att den var bra och att jag jobbade bra. Det känns skönt och härligt nu efteråt."

Bemötande från de vuxna är en nyckel till att metoden har varit framgångsrik, och i sina instruktionsfilmer på webben framhåller Barnombudsmannen återkommande vikten av att de vuxna som ska möta barn och arbeta med 
metoden ska vara väl förberedda och ha bra barnkompetens.

"Det märktes att de vuxna lyssnade när jag pratade, de tittade på mig och nickade när jag sa något," berättar Otto. Han visar med hela kroppen hur en vuxen som lyssnar ser ut och fortsätter:

"Det finns många vuxna som lyssnar i skolan och så, men ibland avbryter och dömer de på förhand innan barnet har hunnit förklara eller prata till punkt. Och ibland har de inte tid att lyssna ordentligt."

När Otto ska berätta varför han tycker det är viktigt att delta blir han väldigt engagerad. Det är tydligt att erfarenheten att vara med $\mathrm{i}$ "Unga direkt" har gjort avtryck.

"Det känns jätteviktigt för mig att göra det här! Om inte jag gör det så vet folk inte hur jag har det, och då kanske de bara gör saker och fixar för barn som inte har samma funktionsnedsättning som jag. Därför måste barn med olika åsikter vara med, och personer som jag med funktionsnedsättning."

Alla länder som har ratificerat barnkonventionen rapporterar till FN hur de uppfyller den. När Sverige frågades ut av barnrättskommittén i januari 2015 var det tydligt att Barnombudsmannens arbete och rapport till kommittén hade fått stort genomslag. Bland annat lyfte kommittén bristen på statistik om brott mot barn med funktionsnedsättning som problematiskt, uppmanade Sverige att säkerställa likvärdig tillgång till skola för alla och tryckte särskilt på vikten av att lyssna systematiskt på barn med funktionsnedsättning.

När dåvarande barnombudsman Fredrik Malmberg reflekterar över att rapporterna fick så stort genomslag lyfter han att "Unga direkt" ger röst åt barn som lever i utsatta livssituationer.

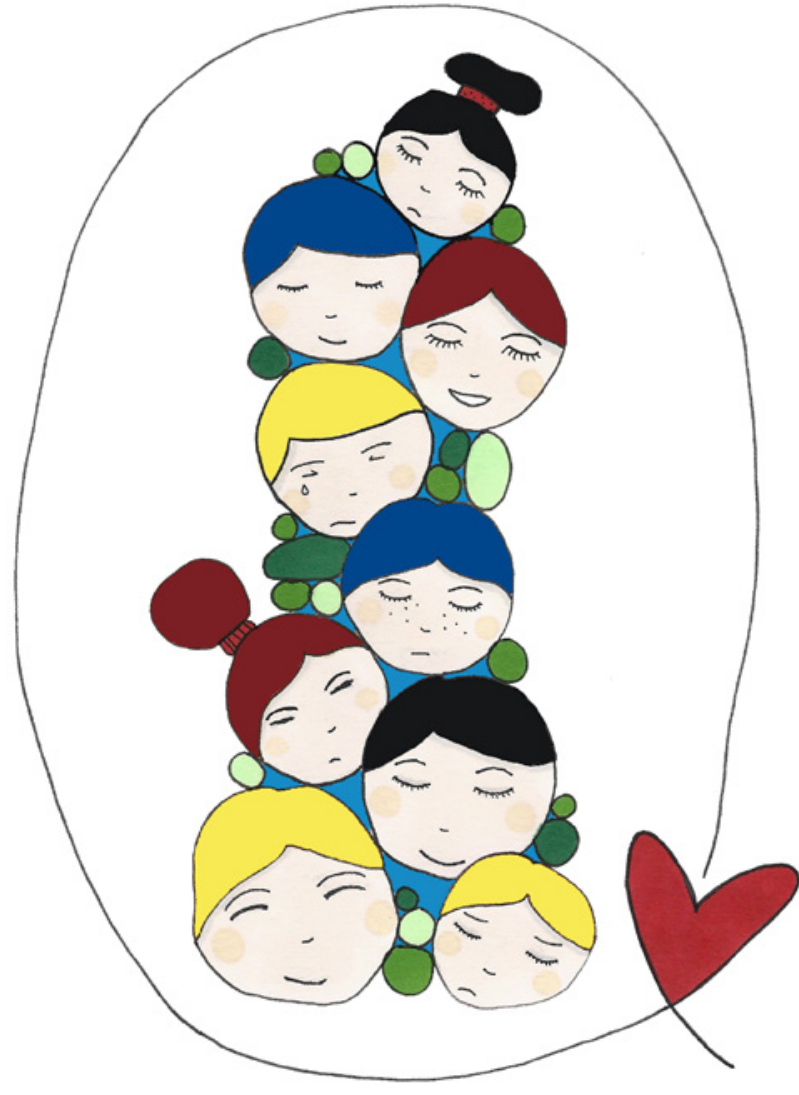

"Jag tror att styrkan i våra rapporter handlar om att barn som normalt aldrig hörs fick komma till tals. De problem och rättighetsutmaningar som barnen pekade på kunde vi sedan granska med stöd av andra undersökningar och i dialog med berörda myndigheter. Våra rapporter avslöjade och fördjupade kunskapen om allvarliga brister i barns rättigheter även i ett land som Sverige. Det gjorde starkt intryck på barnrättskommittén."

Erfarenheterna från "Unga direkt" får också spridning till fler organisationer och myndigheter. Det finns en vilja och en nyfikenhet bland 
flera myndigheter i Sverige att förverkliga barnets rätt att göra sin röst hörd och på det viset bättre leva upp till barnkonventionens krav. Socialstyrelsen har startat ett nätverk för att myndigheter och organisationer ska kunna lära av varandra och dela metoder och erfarenheter med varandra. Fredrik Malmberg har ett tydligt budskap till alla myndigheter och övriga som funderar på att påbörja arbetet med att ta in barns röster i verksamheten:

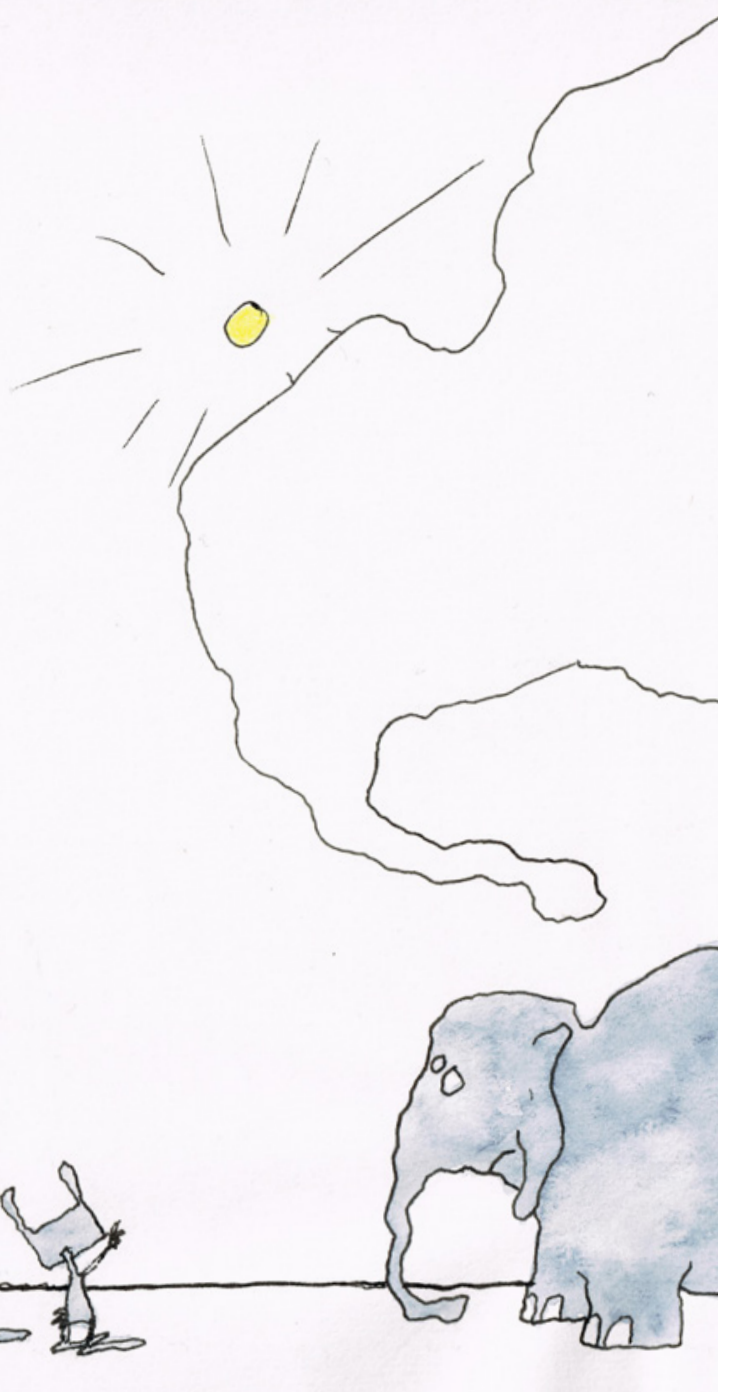

"Gör det! Ni har allt att vinna! Besluten blir bättre underbyggda, misstag kan undvikas och sedan är det förstås också så att barn har rätt att komma till tals och bli hörda inför viktiga beslut som påverkar dem."

Från Barnombudsmannens sida framhåller man att "Unga direkt" inte är ett kortsiktigt projekt, utan ett sätt att långsiktigt möjliggöra för många olika barn att bilda och uttrycka åsikter. Metoden används återkommande varje år vilket gör att beslutsfattarna också vänjer sig vid att barns röster är att räkna med, och att de både själva och genom starka organisationer kan kräva sin rätt. Och det i sin tur är en förutsättning för att förverkliga barnkonventionen.

"Det som är bra med "Unga direkt" är att den ger barn och unga möjlighet att komma till tals på sina villkor med hjälp av flera olika kreativa verktyg. De svårigheter som finns handlar inte om metoden, utan om att det krävs tydligt stöd från myndighetens ledning och att tid avsätts. Barns deltagande måste vara på riktigt," säger Fredrik Malmberg.

Otto lyfter också andra aspekter på varför det är viktigt att vuxna lyssnar på vad barn berättar om sin situation.
"Det är ju svårt för vuxna att veta vad barn vill i dag, det är ju inte lika som när de var barn. Så vuxna måste lyssna på barn i dag för att få reda på vad barn i dag vill och be- höver."

Otto avslutar med att sammanfatta varför han tycker att det är viktigt att barn med olika förutsättningar får chansen att komma till tals och uttrycka sig: "Alla människor är lika mycket värda - och
jag har ganska mycket att säga." 


\section{$\mathbb{1}$}

\section{Nordiska ministerrådet}

Nordens Hus

Ved Stranden 18

1061 København K

www.norden.org

Barn är experter på sina egna liv och har därför viktig information att förmedla till beslutsfattare. Detta är utgångspunkten för svenska Barnombudsmannen, som baserar sina rapporter på barns egna erfarenheter. Metoden "Unga direkt" har som syfte att hitta och lyfta unga människors röster direkt - utan vuxen justering eller tillrättaläggning. Det är en ovanlig, men allt mer efterfrågad metod hos statliga myndigheter. "Unga direkt" är en kvalitativ metod som används för att lyfta enskilda barns erfarenheter. Det som eftersträvas är alltså inte representativitet för alla barn, utan barn som sitter på expertkunskap om en specifik situation. 